\title{
Phenomenological and Psychodynamic Understanding of Schizophrenia (Silvano Arieti, Eugène Minkowski)
}

\begin{abstract}
Schizophrenia still poses the greatest theoretical problems in contemporary psychopathology. These problems should be investigated through the works of authors who deal with schizophrenia representing different psychological theories. The author takes into consideration psychoanalytic and phenomenological point of view. The statements of those theories are encountered in the field of humanistic psychology.
\end{abstract}

Key words: psychoanalysis, phenomenology, schizophrenia.

In this text I shall deal with the applications of two diverse psychological theories in therapy: one being of psychoanalytical provenance, the other being strictly phenomenological (Spiegelberg). The theories used in psychotherapy are most often burdened with chronic lack of clarity. Thus the attempts translate the notions of one concept into the terminology of another are inefficient, and a better solution is to try to examine the philosophy, and partly also the methodology that forms their basis. What is more, in the analysis of psychotherapy as such, three difficulties should be taken into account. First of all, diagnosis made on their basis is inevitably connected with getting to know the patient, that is with therapy. Secondly, in many of those systems, including the concepts discussed here, therapy (application) shapes the theory, which in turn influences the form of therapy. Thirdly, in order to assess the influence of psychoanalysis and phenomenology in the field of applications, we would have to have a general psychological notion of health, the formulation of which has not been successful so far (Sowa).

The continuators of both psychoanalysis (Arieti, 1974), and phenomenology (Binswanger, 1958, p. 203)) distinguish the explanations of making a diagnosis and providing treatment. In the field of notions discussed here, theoreticians agree as to some philosophical bases of their concepts, yet they differ in their details (Ey, 1996; Minkowski, 2002). Notions used in various languages also happen not to translate mutually (May, 1958b).
Those and other tensions occurring in the literature of psychotherapy should oblige the authors to impose more strict rigours on their thinking, the more strict the more serious the problems that literature has with the notions used. Unfortunately, in the intention of authors of psychotherapy handbooks, the difficulties of terminology are to be dealt with by "folk" psychology, which is neither too scientific nor too philosophical. It is this fact that marks the true decline of psychotherapeutic literature. On top of that, the attempts made by psychologists (Eysenck, Levitt) to examine the efficiency of psychotherapy which, despite vivid discussion have been considered methodologically inappropriate and thus considered closed. Being a supporter of phenomenological psychology I am of the opinion that philosophy should be restored its function of spiritual leadership, lost due to the cult of science, while phenomenological psychology is a good way via which this restitution can come true.

The problem of schizophrenia has been tackled by the greatest theoreticians of psychology and psychiatry, among them: Arieti (1974), Binswanger (1957), Bleuler (1911), Kępiński (1981), Minkowski (2002), and others. Eugeniusz Minkowski is a psychiatrist - phenomenologist, Arieti - a psychiatrist representing a psychodynamic approach. It entails that they apply definite research methods: Arieti - clinical one, and Minkowski - phenomenological one. Both procedures, besides many concurrent features, which I will try to demonstrate, differ substantially. Such a statement may seem trivial, yet in the realm of 
psychopathology the difference between clinical method and phenomenology gives results far from obvious. At the same time, both Arieti and Minkowski work with patients and raise similar issues a (Arieti, 1974; Minkowski, 1966, 2002), assuming that the analysis of psychical disturbances may be helpful in understanding any psyche.

The study of two different ways of thinking in psychology creates the possibility of tackling the problem of naturalism in psychoanalytic theory and in practice at the same time (diagnosis and therapy). This naturalism means application of psychotherapy in the form of impersonal model of treatment, and can be derived from the works of Freud (Szałek, 2004 pp. 91143). I believe that this issue emerges from concepts of man that are basic for psychological theories. I agree with Grünbaum, when he claims (p. 565) that the notion of dynamics is included in the Freudian notion of "neurosis of transference"(Uebertragung). Arieti, who uses the notion of "transference", shares the Freudian understanding of dynamics, comprised in the psychoanalytical theory. In this paper the notions of "disturbance" and "disease" shall be treated as synonyms, for stylistic reasons.

\section{Psychology}

\section{Silvano Arieti and psychoanalytic explanation of schizophrenia}

The monumental work of Silvano Arieti, Interpretation of Schizophrenia, which is the basis of this text, crowned the studies of that Italian psychiatrist on schizophrenia. Arieti shows himself to be a theoretician with imposing competence, and his psychodynamic approach has been groundlessly forgotten (Silver, p. 23).

In line with the positivist tradition, Arieti claims that schizophrenia should be treated both by means of pharmacology and psychotherapy, while the efficiency of the latter is not determined. At the same time, in his clinical work he was unable to define schizophrenia and, what is more, to classify it explicitly as a disease. Finally he stated that this disturbance did not have the features of a disease, as it failed to meet the conditions of Virchow's cellular pathology, on top of that he formulated that opinion in a tone that expressed serious doubts as to the usefulness of this medical criterion in the diagnosis of schizophrenia.

Arieti notices that a psychotherapist should have a theory and follow the compliance of therapeutic procedures with her/his own theoretical convictions. In other words, he believes that the notions used to describe reality, on which psychologist exerts influence, are of enormous importance for the applications. It should be stressed that those propositions are plausible indeed. The Italian psychiatrist is also against the tradition of Kräpelin that each patient with schizophrenia should be hospitalized. He is of the opinion that only persons with acute symptoms should end up in hospital. Although psychotherapy does not eliminate schizophrenia completely, it affects many symptoms of this disease. Arieti obtained best results applying only or mainly psychotherapy for treatment. As he says, pharmacotherapy has its advantages, yet its action is reduced to temporary reduction of anxiety, without triggering defence mechanisms. What is more, the use of drugs reduces the influence of psychotherapy. It is not possible to exceed the genetic barrier in treatment.

Arieti was a representative of a school with long tradition in application of psychotherapy, and has been aware of that tradition. Freud, for example, initially did not see obstacles for treatment of psychoses by means of psychotherapy. It was only as late as in 1923 and 1924 that he claimed they cannot by treated by means of psychotherapy, due to the withdrawal of libido from the object relation to the self (Freud, 1940 a and b). Federn (1953) on the contrary, thought that treatment of schizophrenia by means of psychoanalysis was possible. The topics dominating discussion among psychoanalysts included relations, resistance, transference, fears, etc.

The necessity of perfecting analytic technique has been discussed. Again, some psychoanalysts claimed that the analytic technique applied in treatment (not only of psychoses) should be changed (Klein, 1984, pp. 3-123; 1975), other claimed it was not really necessary (Rosenfeld 1947, 1965). Incidentally, the application of psychoanalysis in the treatment of schizophrenia generated ethical disputes. They concerned, for example, a very controversial Rosen therapy (Masson, pp.159-178). Melania Klein claimed that at the moment of birth, the Ego is developed enough to experience anxieties which may contribute to the development of schizophrenia, and applied drastic interpretations in the treatment of children (Klein 1984, pp. 123-279; Szałek 2004).

Arieti defined himself as a continuator of the approach used by Frieda Fromm - Reichman, who supported a psychotherapeutic approach according to which a significant part of etiology of schizophrenia is composed of psychological factors, and even if it is not so psychotherapy prevents the disease from recurring. The relationship between patient and a psychotherapist in line with the postKlein psychoanalysis has been referred to as relatedness by Arieti. The very notion of "relation" was understood by the Italian psychiatrist widely, and signified communication, interaction, and social contact. The key to understanding the psychical life of the patient was relatedness, outside of it there are no effects of psychotherapy. That is why the Italian psychiatrist did not believe in spontaneous healings and claimed they were always a consequence of a hidden relation - for example - between the patient and various members of hospital personnel. Such a relation that "happens" could occur accidentally, while participation in it was the reason for remission even of advanced schizophrenia. Unfortunately, the absence of theoretical studies concerning the problem of relatedness resulted in incidents of repeated hospitalization of patients with apparent remissions, as they were not always prepared to function in actual social conditions. The establishing of relatedness was an initial, pre-scientific stage of treatment, the distinguishing feature of which was that even the most autistic patients do not resign from communicating with other people completely. 
After Sullivan, Arieti also claimed that the basic condition for a psychotherapeutic situation to occur is that the patient needs to feel safe. In order to trust himself and the world the patient must, with the assistance of therapist, develop suitable resources in himself. Unfortunately, it is very difficult to establish an object relation with someone who renounced reality and who experiences growing anxiety in subsequent contacts. In many cases, patients' symptoms may be the guide for therapist. Patients in the state of panic, actively de-compensating, require active and intense intervention, giving the sense of protection of basic trust. Even non-verbal messages may be directed to them. The slogans of humanistic psychology undertone in the following pieces of advice: ,the therapist must clarify and distinct his entity as an unsophisticated, straightforward, simple person who has no facade to put on, a person who can accept a state of non-understanding, a person who has unconditional regard for the dignity of another human being, no matter what is his predicament" (Arieti, p. 548). Creating such a relatedness, the therapist must avoid premature interpretations, and sometimes one simply has to hold the patient by the hand. In order to understand a person suffering from schizophrenia, one has to know the dynamic features of that disease, among which Arieti lists the influence of family, for example.

During contacts with autistic patients, Ariet recommends ways of behaving taken from the stock of cognitive and behavioural therapy: avoiding to look in the patient's eyes, which may cause increased anxiety in the patient, as well as formulating short and concise messages. Such a behaviour is not allowed in case of patients with dumb catatonia. In such cases, the patient should recognize in the therapist's tone of voice that the therapist came to "cut him out" of the blurred world. Bearing in mind that the patient may escape into stupor at any time, the therapis should open neutral topics, formulate nice sentences, and avoid touching important issues. During such a session, the silence and non-verbal communication is interrupted by the strong voice of the psychotherapist. The therapist sometimes has to wait a long time before the patient provides him with material needed for historical analysis, but even in the wordsalad uttered by paranoiacs and hebephrenics, something important can be found.

It should also be remembered that a psychotherapist may experience anxiety that is even greater than that of the patient, which results from the feeling of nonsense in patient's speech. Such a feeling causes, whatever the volition of the therapist, destruction of his feeling of solidarity with the human race. The treatment provider sometimes feels that he both grasped the meaning conveyed by thoughts of the patient, and that it escapes him, too. In order to understand the world of a schizophrenic, the psychotherapist should share with him the de-socialization and individualism. The understanding of the patient comes as a consequence of intuition, similar to that which occurs between mother and her child, when in their relation archaic symbols become social ones.

Relatedness is threatened with personal problems of the patient, which cause her/him to attach special importance to what s/he says. The staggering exchange of meanings in such a situation results from impairment of non-verbal means of communication. The patient understands the emotional tone of voice of the therapist, increases her/his sensitivity, and reduces comprehension, adding ego-centric interpretation to this emotional tone, experiencing several desires $\mathrm{s} /$ he simultaneously increases her/his problems with communication.

The smaller the portion of patient's psyche affected by the disease, the less time it takes to make an objective diagnosis, and the more time is devoted to empathic techniques. Some patients may be suggested free associations, but that applies only to those, who do not show signs of regression. Also, drastic associations should not be interpreted. The application of free associations should be rare in a conversation establishing relatedness, while patients should see the therapist during such a conversation. Attempts may be made to convince talkative paranoiacs to avoid their delusions and strengthen their relations with the world.

In Arieti's opinion, transference and countertransference do occur in persons suffering from schizophrenia, but not in the sense of classic psychoanalysis. It ensues that the phenomenon of transference will be examined as a comprehensive, mutual relation and to do so certain of its aspects should be understood first. Nevertheless, the understanding of transference, as an act of relation, should be the main thread in work with the patient. In consequence, for Arieti - although he did not say it openly - in treatment of schizophrenia communication became more important than being faithful to theory.

In order to understand relatedness, one has to discuss with the patient his transference first. Social contact is often perceived by the person suffering from schizophrenia as a threat endangering her/his existence. Patients with schizophrenia are inert, suspicious, persecuted, tormented with the feeling of emptiness, and dynamic psychotherapists do not belong to their world. It happens that "the patient may change abruptly, and have some warm feelings towards the therapist; sometimes the patient changes very slowly and changes are almost imperceptible. These quasi-static patients seem to live in an almost magically timeless world. Therapy makes time re-enter into their life. But at first the therapist's (and the patient's) time is not society's time" (p. 556). A patient who accepted the therapist begins to approve of his/her environment. This bringer of transference that occurs, later serves the interpretation made within relatedness.

Another proposition made by Arieti results from the traditional standpoint of psychoanalysis. The Italian psychiatrist claims that the analysis cannot be premature. Paranoiacs, for example, anticipating rejection, locate therapists within their delusions and reject them. In such a case, suspicion may lead to the generation of „malevolent transformation"( p. 557) and disturb every aspect of relatedness, which will be closed in paranoia. This kind of relatedness needs to be treated immediately, even disregarding interpretation, as the increase of strength of that relatedness may destroy all progress in therapy. 
Every schizophrenic patient experiences hostility, which results from her/his past relations. The psychotherapist demonstrates to the patient that his anger is directed wrongly, as it is related to the past, which seemingly has not passed. Patients also happen to be openly hostile, by which they demonstrate that they feel too weak to establish a relation. Psychotherapists then intuitively recognize the patient's history in the perspective of her/his present difficulties Arieti also discusses the specific difficulties that occur in the treatment of people who are excessively submissive.

Another problem discussed by that Italian psychiatrist is the analysis of countertransference. In fact, the therapist must firmly believe in her/his abilities and identify with the patient in a way similar to that in which parents identify with the suffering of their children. The doctor must replace the impaired mother-child relations with new, functional ones. In this context no compensation of earlier irrational behaviours is possible, unless the therapist in her/his work brings about the functioning of adult components of patient's personality. The analysis of therapist's feelings must begin the treatment, as efforts to hide them are futile and the treatment provider sees in the patient a transformation of his problems, anyway. The therapist must demonstrate devotion to the patient, yet not friendship or love; also s/he should not be too sociable.

The patient's problems result from the extremely severe superego, which represents the influence of parents. For that reason, the situation of transference should be similar to a genetic one. However one has to remember also that most therapeutic benefits will be obtained from the analysis of dissimilarity of those two situations. On the other hand, therapists unconsciously look for patients with problems similar to the ones they have themselves. People suffering from schizophrenia are egocentric and it seems to them that the negative feelings of the psychotherapist refer to them. In therapy these persons may receive numerous signals, but Arieti does not agree with the proposition that their observations are of extraordinary insight.

After discussing relatedness in categories of transference and countertransference, Arieti analyzes the second aspect of relatedness. It is the common experience, as a result of which the patient and therapist learn how those feelings are experienced in "repeating mutuality" (Arieti, p. 568), the other side of relatedness. Thus, the patient and therapist become persons who cannot exist one without the other, while the theoretical justification of therapy boils down to establishing a relation between human beings which is not attainable even in relation between healthy persons.

In psychotherapy, a therapist must often be satisfied with the exchange of trust and warmth, as well as the advancement of patient from deep alienation to true communication. This advancement does not entail Freudian abreaction, but breaking autism that is the barrier of lack of contact and de-socialization that may occur through factors not related to psychoanalytic procedures. When a breakthrough occurs in therapy, it becomes object oriented. In other words, the relatedness of therapy is threatened by the fact that the psychotherapist must, initially, cope with the traces of child-parent relation in his work, "but, therapeutic relatedness will be maintained if it is based on basic trust... The therapist is experienced as a human being who believes in the potentialities of the patient, and who with his trust, understanding, and devotion facilitates the unfolding of these potentialities" (p. 569).

\section{Schizophrenia according to Eugeniusz Minkowski}

Minkowski did not undertake the task of providing a full description of schizophrenia, and wanted to point out to certain consequences which his understanding of that disease had for psychopathology. In other words, he wanted to find an answer to the question concerning the way in which a person deprived of the ability to digest any conscious content in which movement and duration occur, tries - against all odds - to direct her/his behavior by means of such acts of consciousnes which in normal life are the domain of logic and mathematics only. Those acts contribute, in consequence, to the preservation of static image of the world. Minkowski's considerations were illustrated by two cases of the disease.

One of Minkowski's patients complained about the feeling of emptiness, including meaningless processes, comparable only to sialosis. He communicated in a lifeless voice that he felt he moved back in time. $\mathrm{He}$ had no hallucinations, no delusions, nor any reduction of intellectual functions. Despite that, soon after the first conversations with him the French psychiatrist had a feeling that his disease was serious indeed and that feeling increased later. The patient had a long history of interests in philosophy, He put down his thoughts, and gathered quite a file of notes. However, he did not read the works of philosophers in order not to "spoil" his thinking. What is more, he remained in isolation from the world to derive his philosophy from himself. The definite diagnosis was: severe and advanced schizophrenia (Minkowski, 2002, p. 128).

Everyone of us sometimes feels the need to try and find strength for life and work in herself/himself, Minkowski claimed. At the same, attempts at finding the strength only in oneself cannot be equal to avoiding any external influences. Temporary isolation serves merely the purpose of Re-assembling the elements coming from the external world, in order to use them as the material for one's own action, while the assessment of strength of the need to be isolated from the world or to remain under its influence is subjective. The balance of isolation from and participation in the world is an extremely important element, serving the purpose of regulation of every individual life, being its irrational component. The answer to the question asked at the beginning will not thus be validated by logic but by intuitive feeling of harmony with life.

Irrational factors, in the opinion of Minkowski, glimmer in the depth of consciousness in case of every more serious situation man faces in life. When an individual, in a situation of conflict between the need of isolation and the willingness to participate in external life in contact with other human beings, does not know how far to limit the influence of situations upon consciousness, s/he takes the 
decision thanks to an irrational factor, subjectively and smoothly. This condition posed by life is the source of the notions of limit and measure, which no intellectual act is capable of defining. Paraphrasing Pascal, Minkowski says: "life has its reasons, which the mind would never be able of pronouncing" (p. 130).

Minkowski's patient failed to gain the ability of integrating with reality. On the contrary, he made reality a tabula rasa in which he found no natural support, and either "got lost in the clouds" or "drowned himself in reflections". The isolation which he rationalized was deeply connected with his libido. It caused the patient to escape from books, thus also from people who wrote them; as a result he lost the information they contained about how rich and mobile life can be. Even a very intelligent man who wants to act paying no attention to other people or external incidentiality makes his way to error and practical absurdity. The tasks of life are understood by such a man in categories of rational antitheses (good - bad, just - unjust, etc.), which testifies to absence of non-intellectual contacts with real life. The behavior of Minkowski's patient has been governed mainly by thinking, which worked fine in the assessment of mathematical problem but became morbid and dangerous when it was to govern practical things. The aim after which a man strives is in fact being in agreement with the process of life, not with the abstract rules of logic.

Minkowski's patient, striving to reach spiritual perfection excluded physical work from his life previously he used to devote much of his time to bee-keeping before he fell. He treated his parents' discussions about money as something against his ideals. His reasoning was logical, yet the content of his thoughts, although formally correct, led to devastating consequences. This happened because his thoughts concerned a life that is not subject solely to universal rules but also, to a similar degree, to irrational factor which is present in every living creature.

The patient tried to separate himself from matter and describe himself in the form of impersonal rules. He claimed that true happiness is in attaining wisdom. To achieve it one has to live alone and give up the earthly foods which may be an obstacle in achieving that aim. He tried to establish a system of thinking, assuming once a week a rule that would properly arrange his behaviour, e.g. the principle of justice, of moderation, and of silence first of all. Then he stopped talking and answered the questions only if they suited his principles that constituted a sieve through which he filtered his words.

The patient's disturbances occurred when he took the liberty to speak in too impulsive manner, not complying with the principles of exclusive rationalism. Working as a teacher, he applied the principle of unlimited tolerance towards his utterly irresponsible students. He incessantly strived to reach their brains, and suffered enormously seeing that they laugh at him. Then, implementing the orders of the headmaster, he became excessively strict, only to switch to the principle of unlimited liberalism later on. He treated each foreign element which exerted influence on him as something that threatened his entire personality, and saw signs of imminent catastrophe everywhere, assessed all the influences of reality through one category, in which $\mathrm{He}$ located the sense of embarrassing external influences, as well as exultations.

In fact, the bonds an undisturbed individual has with reality are infinitely richer. In an attempt to dominate the world individual may try to impose her/his will on others, but at the same time is able to obey when an order has been given, or give way to love or mercy, thus surrender to feelings without experiencing them as a threat to freedom. The patient's awareness functioned only within the following two categories: his independence that functioned in the form of radical intellectual antitheses, and painfully felt influence.

The patient's speech got distorted, in his opinion, after some suggestions made by his parents, when he felt forced to "rape" his voice and to express thoughts that were not in line with his principles. As a result he, who previously felt a master of his looks and words, lost his self-control. Before the disease started, the patient's words as well as the unconstrained way of speaking were - in his opinion solely a fruit of his own reflection. Later, when teaching, he felt restrained by the sound of his voice and look, which he passively offered his the students. At a certain moment he began to feel disgusted with teaching, as he considered that the headmaster whom he respected enforced his rules upon him.

When listening to the patient, Minkowski had the profound impression that there was a factor which merged all the patient's symptoms, a factor that the patient did not realise but which was important, taking into account the basic elements that regulate life. He made some kind of intellectually cohesive system of the symptoms which destroyed him nevertheless and alienated him from the surroundings. In Minkowski's opinion, there is a special kind of contact with the surroundings that is vital, and the disturbance of it resulted in the occurrence of yet another disharmony, not noticed by the patient. His awareness appeared to him like an arena, on which impersonal abstract principles struggled. As a result, his entire psyche also made the impression of being impersonal. For example, his students interested him only as much as he perceived them through the doctrines he applied in life. As a result, in his opinions there was nothing personal or warm. He lost completely the ability of having unison "vibes" with objects i.e. people, the possibility which connects every individual with the intimate personality of another man. Where such a lack exists, every personal contact is broken, and a man is unable to look at persons in his surroundings in a way that would be in line with the demands of life, and escapes towards deserted and icy areas of consciousness, governed by pure intelligence. The interests of such an individual seem even wider than average, but in reality they reflect only the extreme poverty of spirit, deprived of everyday stimulations related to life.

Minkowski's patient first limited the influence exerted upon him by people from his close surroundings, and then he imagined that all the world exerts influence upon him. In consequence, he lived treating people impersonally, indentifying not with them but with the abstract humanity, 
trying to get close to the equally abstract absolute. Because of such communication, innocent disputes that take place between children and parents in expanded his imagination to the size of a truly titanic struggle.

His parents, worried because of his strange behaviour, tried to alleviate the symptoms by means of commonsense interventions: the father used to say "if you are not able to carry a load of one hundred kilograms, we should carry fifty", yet the patient was not able to assess measure and give the parents' spontaneous reactions their due place, and saw in the pieces of advice given only a threat to his ideals. This resulted in his referring to the "dangerous influences" to which his personality has been exposed, and treating every commonsense concession made as an act of utmost importance. The patient lost the ability of influencing individually specific persons and objects, seeing them only from afar and magnified.

Studying the life story of the patient, Minkowski had the impression of him following not a flexible continuous line, but a line that is continually broken and irregular, representing thoughts that oppose each other and fight against each other and are labeled with strange names, that are attached to individual stages of his existence. Each of those thoughts was completely isolated from the previous one, the same way that a rule governing a given thought completely contradicted and excluded the one which followed. Emotional factors seemed to vanish from the mental life of the patient which was incessantly in opposition to life.

Another patient excessively generalized spatial notions and introduced into them an unhealthy domination of mathematical theorems, defining the value of objects and incidents merely by means of their size and geometric description. At the age of sixteen, he started to trouble himself with the issue of structure and whether the walls of the school building are straight, or how it was possible for the church roof to be supported only on pillars and keystone.

Later on he developed a mania for symmetry and "obsession of pockets", which was expressed by the question: what is the difference between the impression experienced when one puts his hands into straight pockets and the impression experienced when one holds his hands in the curved pockets of a coat? He would stand in front of a mirror, looking for absolute symmetry in it, and perfect position. When he served in the army, he received injections of sodium cacodylate. At a certain moment he began to think that a piece of cotton wool could have penetrated his body together with the content of the syringe. This obsession intensified particularly by the constructing of geometric structures in the patient's imagination, and by notional reasoning. In the patient's thinking, geometry, plan, and logic exceeded in perfection everything that constitutes the richness and mobility of life. Anything irrational, which was the basis for change and development, was excluded from his psyche. He said: "a plan is everything in my life. I do not want to do any harm to my plans, at any price. I stand more in the way of life than of plans. It is the fondness for symmetry and regularity that attracts me to my plans. Life does not demonstrate regularity or symmetry, that is why I create reality myself. I attribute all my strengths to the brain" (Minkowski, 2002, p. 141). When pondering about the impression a woman's body makes on a man, the patient asked whether spherical shape is not the impression of highest beauty.

Leaving the hospital, the patient took with him all bottles and drug packaging, and then he meticulously arranged them at home, to have a proof of where he stayed. He said he was looking for immobility, and had the tendency to immobilize life, that is why he liked immobile objects, boxes, bars, things that always existed and never changed. He did not trust the Earth, as it was moving continuously and he attached importance only to solidity. A train riding on an embankment was of no importance for him, what mattered was the embankment itself. The patient treated the past as a precipice, and future as a mountain. One day he decided to leave behind the difference between them and did not urinate for 24 hours. Then he wanted to move back in time and return to the impressions he had fifteen years ago, which for him implied death, with the feelings he supposedly had when he came unto this world.

The patient's awareness, Minkowski claims, has been composed only of immobile geometrical and spatial objects liberated from the influence of intuition i.e. the dead objects. Their creation began in the patient's psyche from presuming certain ideal assumptions, and reached monstrous conclusions. Minkowski's wife, observing the patient stated that in his awareness life resisted plans, instinct denied mind, and impression denied thinking. The synthesizing ability of penetrating phenomena was juxtaposed with the analysis of unimportant details. Where an undisturbed person would trust impression, the patient demanded proofs in a world where movement denied the truth of immobility, while events and persons were opposed to objects, execution had no connection with representation, time with space, consequence was in opposition to extension, while aim was in opposition to the basis. The patient, having lost the sense of instinct, became a man who felt comfortable only in infinity, immobility, and death that allows to escape all that is new at any moment of history, and which is characterized by the natural incomprehension of life (Minkowski, 2002, p.144).

The ways of thinking of the two patients described by Minkowski were characteristic of schizophrenia at every stage of its development. Invariably, there was loss of dynamic sensual contact with reality as well as of feelings related to that contact, excess of intellectual factors taking the place of dynamic emotions, which were missing in the time lived. As a result, persons suffering from schizophrenia precisely described the time in which they perform a certain activity, taking still objects as "witnesses". The thoughts of such persons transgressed the border of each object that appeared and identifying with it they expanded in infinite space. For example, noticing a piece of newspaper resulted in ruminations about all its copies, followed by ruminations concerning all press clippings of all French newspapers. As a result, in such thoughts the understanding of individual range of objects, events, and people disappeared or escaped into endless space. The pathological rationalist wasted a lot 
of time to determine the plan for the day which - due to being too precise - he could not implement later. Chronological terminology, in case of people suffering from schizophrenia was replaced by topographic one, as for example in the sentence "I will go where, (instead of "when", P.S.) the hour strikes outside" (p. 148). In many studies and clinical cases Minkowski finds ontological propositions that are in line with Bergson's philosophy, and which he considers to be a philosophical remedy for solipsism (p. 151).

\section{Naturalism in psychotherapy}

An example of treating psychoterapeutic techniques in naturalistic way may be a certain mutation of the procedure applied in anxiety disorders, referred to as the exposure therapy. In general terms, it consists of exposing the patient to anxiety situations, so that such a situation becomes obvious and not threatening to the patient. The notion of "habituation of fear" is used for that purpose (Reinecke, Clark, pp. 272-274). The point is that fear sensations become everyday ones, and lose their torturing power in a person who had been exposed many times to definite fear stimuli. Gradual and "immersive" habituations exist, the latter concerns subjecting the patient to extremely intense stimuli.

In cognitive therapy (Beck) the assumption is made that the intensity of fear may be connected with specific amounts. One can imagine two cases: 1 . The therapist, not consulting the fear strength with the patient, exposes the latter to an "immersive test"; 2. Before the exposure, the therapist introduces scaling in a conversation, and starts the exposure with fear of maximum strength that is bearable to the patient. Incidentally, the latter is in congruence with the guidelines of cognitive - behavioral therapy. I refer to the former one as naturalistic, the latter being humanistic. In the former the therapist introduces the steps of therapy without asking the patient's opinion, in the latter s/he communicates with the patient in the course of therapeutic process.

In one of the cases, the patient experienced strong fear when a thought occurred to him that he can sign a document without being aware of it, which could later on contribute to his total legal incapacitation, impoverishment, or other disasters in life. As a result, he initially avoided all situations in which signing was involved. Then he stopped writing anything, at the post office he photographed all signed documents dozens of times, which resulted in generation of hundreds of photographs in his mobile phone which he stopped using for calls, anyway. It has been found out that the patient was able to withstand the fear occurring during a telephone conversation with the therapist only during a visit paid to the therapist, when the latter was present in the same room, at a certain distance from the patient. The other situation that was tolerable for the patient was scribbling a few words on a piece of paper, which the patient could take with him. After exposure, the obsessions and compulsions, even those ranking above the estimated fear strength that would be tolerable, lost their power to such a degree that the patient could effectively function in social environment. It entails that a technique which is "friendly" to the patient may be as effective as procedures applied in a medical way, and the entire exposure procedure does not need to be brought to the extremes.

In the example provided, elements of humanist therapy are well delineated. First of all, the therapist must assume that the patient has a certain ability for introspection, ability to speak, intelligence, thus that it is possible to communicate with the patient. The proposition of relatedness of psychotherapy is included in that attitude. The second element illustrates well the differences between humanistic and naturalistic therapy. Namely: a doctor may or may not like the patient, but would not agree anything with her/him. He makes a diagnosis and prescribes medication Having the experience and specialist knowledge the doctor prescribes medication in a way in which tools are used, unless his patient is also a doctor.

\section{From naturalism to humanistic psychology}

\section{Philosphical inspirations of Silvano Arieti}

A psychotherapist, in his relation with the patient, maintains certain standards developed in medicine. He should as thoroughly as possible, get to know the symptomatology and origin of symptoms, which roughly corresponds to etiology. He should also be aware of the existence of two aspects of his work, which may result from various philosophical sources, and which sometimes result from popular psychology. Those threads have been examined by the Italian psychiatrist in the perspective of the relation of transference, while the kinds of transference in schizophrenia which he has written about are referred to by psychoanalysts today, as well (McWilliams).

From Vico and thanks to that philosopher of the Enlightenment, Arieti assumed the development perspective in perceiving man, and understood the human way of perceiving the world (Arieti, 1974, p. 546). What is more, in his reflections concerning human reasoning the Italian psychiatrist reached for the concept of primitive thought (Lévy-Bruhl), which resonated also in other psychological concepts of the 20th century (Jaroszewski, p. 257). One of the manifestations of this thinking is identification, excessive and simplified at the same time. The patient identifies with all women the way he identifies with his sister (Arieti, 1948, 1974, pp. 229-241). Arieti is also a successor of the thought of Heinz Werner, who claims that advanced Aristotelian thinking is not the necessary crowning of development processes, but one of its possible results (Arieti, 1974, p. 232). The forms of thinking of older provenience, which Arieti refers to as palaeolithic one, remain in contact with its more recent forms (Arieti, 1948; 1974, pp. 241-243)

Analyzing the notion of development, Arieti strives in all possible ways to remove the curse of naturalism from Freud's concept, and he is not the only theoretician involved in this strife (Stern). The aim of theoretical justification of the applicability of psychoanalysis in treatment (of schizophrenia) is very difficult indeed. It turns out that, in line with certain psychoanalytic theories, Freud's theory 
may be applied in the psychotherapy of schizophrenia, according to others it may not be applied, still others say it is possible, but after subjecting Freudism to farfetched modifications (Cioffi, Crews). One does not need to add that such conclusions are lethal for every theory. The results are even worse for the "humanizing" assurances of the theory criticised for drawbacks in practicing, that the inventor of psychoanalysis wrote one thing and did another (Kutter, $p$. 67). Defending Freud from Freud in this case consists in justifying what is not in the theory by means of what does not result from it.

The inventor of psychoanalysis locates human psyche between biology and the influence of culture. This area contains mechanisms which allow to transform biological factors into mental processes. Conflict remains the driving force of development, both between biology and cultural factors in personality, and within that biology and those factors. It is examined by a psychoanalyst, to whom Freud entrusted the role of the gate keeper (Gellner, p.161) who lets the stray patient to the garden of truth. The first gate keeper was "sure of himself, arrogant, unmoved in his faith. He destroyed everything, but never took the pain to think over what he announced to the world" (Gellner, p. 168). This is the example of a therapist, with whom Arieti struggles, more or less explicite. I have no doubts regarding his humanist intentions. The erudition of the Italian psychiatrist is imposing, while the manner of presenting the propositions is beautiful. At the same time, attempts are still made to reconcile Freudism with humanistic thinking in psychology (Frie).

In order to properly arrange the symptoms which arose in the conflicted mental life, Arieti made use of the achievements of clinical psychology and psychiatry. They were established in the process of historic, repeated discovery of the existence of specific phenomena for example the manifestations of schizophrenia. It is a procedure which is "statistical" as a matter of fact, in that the basis for diagnosing the disease and selecting a therapy is the amount of observations in clinical practice and their repeatability. This clinical-nomothetic focus of the Italian psychiatrist results in the fact that Arieti writes in beautifully about time, but that time is not a subjective experience, but only its circumstance. For psychoanalysis the clinical and medical way of studying the conflicting mental content occurring in transference was a substantial challenge.

\section{Philosphical inspirations of Eugeniusz Minkowski}

The psychological propositions formulated by Minkowski were under the strongest influence of $\mathrm{H}$. Bergson's philosophy, which became out of fashion before Minkowski made use of it (Kołakowski, 2004, p. 5). Bergson influence the concepts of the French psychiatrist making use of the fact that philosophical projects - just like works of art "do not become obsolete in such a way that they are replaced: they preserve their individual value" (Kołakowski, 1967, p. 37).

According to Bergson, the process of evolution is the realization in matter of the intentional influence of dynamic creative force. One of the manifestations of the dynamic stream of life is the mind. Although it has been created in "determined conditions, in order to affect determined things", yet it alone cannot grasp all the processes of life, of which it is but a certain side (Bergson, $p$. 33). The continuity of life is realized in the endless amount of its variants, arising in no matter how small a unit of time. Rationalized mind is not capable of getting to know them. It contains, however, in a certain cognitive action the traces of lost instinctive functions, that action being intuition. It is intuition that allows to perceive the dynamic processes, established in its non-printable multitude by memory, as something "not thought but experienced" (p. 44). In Minkowski's concept, time is not an ordinary circumstance of mental phenomena, but their unique experience lived through $(1999,1933)$.

As Arieti noticed rightly, for psychologists of phenomenological orientation the most important thing in the description of an individual was to examine how the person affected by the disease experienced time and space, as particular and at the same time basic framework for all phenomena. Man experiences time in various ways, time that is different when we say: "that time, it was short moments of happiness" and different still when we describe it as "time of endless boredom". An individual may experience time, which does not exist physically, as when s/he is afraid of the future. Time and - what follows - the image of the world may also stand absolutely still. Symptoms do not occur in time but are manifestations of various ways of experiencing time. The patients examined by Minkowski lost a substantial portion of intuition, which caused the generation of a series of static time-images in them (Binswanger, 1958).

Authors of phenomenological theories also deal with the problem of eidetic method (Minkowski, 1933). In this respect, those theories are rarely cohesive as regards notions, as for psychology. The attitude assumed in methodology by Minkowski is the specific "subtraction" from the phenomenon of non-phenomenal content occurring in consciousness, for examples theories, convictions, assumptions, shortly - any "hypotheticality" (Binswanger, 2011, p. 34). Phenomena understood in such a way can be grouped logically as signs of particular complaints. Understanding of symptoms occurring in the awareness of a patient entails that the therapist enters the world of the disease on the grounds of forming a language community with the patient. The entire process is one of the forms of communication (Rudziński, p.99). This step, by joint (patient's and therapist's) understanding of logical basis of symptoms opens the ways for transformation of that disease.

Schizophrenia is a disturbance manifesting a huge variety of symptoms in all areas of mental life. A doctor-phenomenologist would ask what connects those symptoms. Phenomenological method led Minkowski to the results which are both original and congruent with later formulations of schizophrenia. As noticed by Kępiński "in doubtful cases (regarding diagnosis - P.S.) the feeling of being different and strange remains, something that in 
German terminology of psychiatry has been referred to as Präcoxgefühl...". On the basis of occurrence of that feeling, a diagnosis is often made ,....although it is not a scientific method yet, as it seems, it gets down to the crux of schizophrenic expression" (Kępiński, pp. 27-28). In my opinion, this particular feeling of being different has its source in intuitive grasping of patient's time specificity by the therapist.

Experiencing the world by a person suffering from schizophrenia resulting from "over-rationalisation" inevitably leads that person to a breakdown of the timespace structure of this world (cf. Kępiński, p. 217). In consequence the diagnostician and the patient function in different time. The feeling of being emotionally different begins at the source - the existentially different patient's time. The therapist, trying to pronounce notions that are adequate for the symptom, looks for logical basis for all phenomena of awareness, which penetrate such awareness, manifesting themselves in all spheres of life: habits, superstitions, speech (Binswanger, 1958; Minkowski, 1933).

One should also remember, however, that Minkowski's patients use rational assessment excessively, but in fact their awareness is identical with the awareness of the doctor. The latter, in turn, must be genuinely convinced about the fact, that there is only a difference of degree, not of essence, between a mind that is disturbed and a mind that is not disturbed. This conviction, similar to Präcoxgefühl has the character of intuitively obvious, and implies a relation in which a doctor's patient is a Man from whom the therapist learns. This implication results from the core of phenomenological concept of man, and is not attainable to psychoanalytical thinking (Masson, pp. 109-123). In the end, intuition and understanding intermingle incessantly in the phenomenological- psychiatric method.

\section{Towards synthesis}

Arieti claims that the studies of phenomenologists "enrich our understanding of the schizophrenic patient and will be useful, provided they are complemented by the psychodynamic formal and psychosomatic studies"(1974, p. 696). The objections of practical nature, made by Arieti to Minkowski may be summarized in two points: 1. Minkowski assures that psychotherapy is needed in the treatment of schizophrenia, but he does not say which one, 2. M. says that contact with the patient may be restored, but he does not say how.

Those objectios are based on basic misunderstanding. Arieti, in the footsteps of psychoanalysts, expects ready notions for psychiatry, a set of techniques which - if consistently applied - will liberate the psychotherapist and patient from the nasty multitude of symptoms. Minkowski really does not formulate the rules of psychotherapy, which entail a set of guidelines, that need to be applied in the therapeutic process.

An existential psychotherapist with phenomenological pedigree cares less than a psychoanalyst about specific psychotherapeutic techniques (May, 1958a, p. 76), but Minkowski's philosophy is a therapy in itself, which may but does not have to be supplemented with practical guidelines. His writings contain the thought of psychotherapist's temporary presence by the patient, whereby it becomes obvious that the sense of symptoms is understood, emotional bonds are established, and uniqueness of existence is manifested. The feeling of this obviousness results directly from the phenomenological method of research, and ontology being its basis. Such a presence has been analyzed by other theoreticians, including: Jaspers (Rudziński), Buber (1992) and Levinas (2000). In turn, the issues of synthesis of various directions in psychology has been dealt with by Ey $(1962,1968)$.

Psychological theories change (Paszkiewicz). Moving from psychoanalysis containing a strongly marked naturalist factor to the humanist psychodynamic theory the therapist stops being an objective scientist and becomes a subject of relational social communication, important for the patient. The patient himself/herself is accepted by the therapist as subject of historic development, in which its varieties important for the process of communication get developed (Prouty). The investigation of relatedness assuming conflict-free individual history of an individual, differentiating her/his personality.

I see the possibilities of achieving a synthesis between phenomenological (existential) and psychoanalytic (psychodynamic) theory and therapy in the notions of time experienced and relatedness. The experience of time is a way of life for phenomena that occur in the awareness, relatedness implies awareness of the temporary character of another existence. Those two factors get connected in the jointly experienced time. I do not have much experience in working with people suffering from schizophrenia. Unlike Arieti and Minkowski, I claim that psychotherapy is not effective in case of this disease, but in all the cases known to me, the disturbances of jointly experiencing things with the patient concerned the time without objects, becoming symptomatic in the feeling of loneliness.

\section{Literature}

Arieti, S. (1974) Interpretation of Schizophrenia. New York: Basic Books, Inc.

--------(1948) Special Logic of Schizophrenic and Other Types of Autistic Thought. Psychiatry: Journal for the Study of Interpersonal Processes. 11, 1948, pp. 325-338.

Beck, A., T. (1996) Beyond beliefs: a theory of modes, personality, and psychopathology. In. P.M. Salkovskis (Ed.) Frontiers of Cognitive Therapy. New York: Guilford, pp.1-25.

Bergson, H. (2004) Ewolucja twórcza. L'évolution créatrice. Kraków: Zielona Sowa.

Binswanger, L. (2011) Kierkegaard's influence on Binswanger's work. In: E., Basso Kierkegaard's Influence on the social sciences. John Stuart (Ed.). Ashgate Publishing Limited, Wey Court East, Union Road, Farnham, Surrey, GU9 7PT England, pp. 29-54. (1957) Schizophrenie. Pfullingen: Neske.

(1958) The Existential Analysis School of Thought. In: R. May, E., Nagel, H., F., Ellenberg (Ed.) Existence. New York: Basic Books, Inc.

Bleuler, E. (1911) Dementia praecox oder Gruppe der Schizophrenien. Leipzig und Wien: Franz Deuticke.

Buber, M. (1992) Ja i Ty. Ich und Du. Warszawa: PAX.

Cioffi, F. (2010) Freud a pseudonauka. Freud And the Question of Pseudoscience. Kraków: WAM. 
Piotr Szałek

Crews, F. (2001) Wojna o pamięć. Spór o dziedzictwo Freuda. The Memory Wars Freud's Legacy in Dispute Frederck Crews and his Critics. Kraków: Wydawnictwo Uniwersytetu Jagiellońskiego.

Ey, H. (1962) H. Jackson's principles and the organodynamic concept of psychiatry. American Journal of Psychiatry, 118, 8.

----- (1968) La Conscience. Paris: PUF.

(1996) Schizophrénie, Etiudes cliniques et psychopathologiques. Les Empêcheurs de penser en rod, Institut Synthélabo .

Eysenck, H., J. (1952) Effects of Psychoteraphy: An Evaluation. Journal of Consulting Psychology. 16, pp. 319-324.

Federn, P. (1953) Ego psychology and the psychoses. New York: Basic Books, Inc., pp.375.

Freud, S. (1940)a Der Realitatsverlust bei Neurose und Psychose. In: Gesammelte Werke. 13, pp. 363-368. Frankfurt am Main: Fisher Verlag

Frie, R. (2012) Psychoanalysis, religion, philosophy and the possibility for dialogue: Freud, Binswanger and Pfister. International Forum of Psychoanalysis. 21, 2 pp.106-116.

- (1940)b Neurose und Psychose. In: Gesammelte Werke 13, pp. 387-391. Frankfurt am Main: Fisher Verlag.

Gellner, E. (1977) Uwodzicielski urok psychoanalizy, czyli chytrość antyrozumu. The Psychoanalytic Movement. The Cunnig of Reason. Warszawa: KiW.

Grünbaum, A. (1986) Meaning Connections and Casual Connections in the Human Sciences: The Poverty of Hermeneutic Philosophy. Journal of the American Psychoanalytic Association, 38 (3), pp.559-577.

Jaroszewski, M. G. (1985) Psychologia XX wieku. Psichologija v XX stuletii. Warszawa: PWN.

Kępiński, A. (1981) Schizofrenia. Warszawa: PZWL.

Klein, M. (1975) Narrative of a Child Analysis. The Conduct of the PsychoAnalysis of Children as seen in the Treatment of a Ten-year-old-boy. London: Hogarth Press.

-------- (1984) The Psycho-Analysis of Children. New York: The Free Press.

Kołakowski, L. (2004) Poza zasięgiem nauki. In: Bergson, H. (2004) Ewolucja... op.cit. pp. 5-12.

(1967) Kultura i fetysze. Warszawa: PWN

Kutter, P. (1998) Współczesna psychoanaliza. Psychologia procesów nieświadomych. Modernę Psychoanalyse eine Einführung in die Psychologie unbewußter Prozesse. Gdańsk: GWP.

Lévinas, E. (2000) Inaczej niż być lub ponad istota. Autrement qu'être ou au-delà de l'essence Warszawa: Aletheia

Levitt, E., E. (1957) The Results of Psychotherapy with Children. Journal of Consulting Psychology, 21, pp. 189-196.

Lévy-Bruhl, L. (1992) Czynności umysłowe $w$ spoleczeństwach pierwotnych. Fonctions mentales dans les sociétés inférieures. Warszawa: PWN

Masson, J. (2004) Przeciw terapii. Against Therapy. Kraków: Impuls.

May, R. (1958a) Contributions of Existential Psychotherapy. In: R. May, E., Nagel, H., F., Ellenberg (Ed.) Existence. Op. cit., pp. 37-91. (1958b). Preface. Ibid., pp. vii-viii.

McWilliams, N., (2013) Diagnoza psychoanalityczna. Psychoanalytic Diagnosis. Gdańsk: GWP.

Minkowski, E. (2002). La schizophrénie. Psychopathologie des schizod'des et des schizophrčnes. Paris: Payot.

-(1933) Le temps vécu : Etudes phénoménologiques et psychopathologiques. Paris: D’Artrey.

(1999). Traité de Psychopathologie. Paris: Institiute Synthélabo, Les Empêcheurs de Penser en Rond.

Paszkiewicz, E. (1983) Struktura teorii psychologicznych. Warszawa: PWN.

Prouty, G. (2002) Humanistic psychotherapy for people with schizophrenia. In: Cain, D.(Ed.), Humanistic psychotherapies: Handbook of research and practice, pp. 579-601. Washington, DC, US: American Psychological Association

Reinecke, M., A.; Clarck, D., A. (2006) Psychologia poznawcza w teorii i praktyce. Cognitive Therapy Across the Lifespan. Gdańsk: GWP.

Rosenfeld, H., A. (1947) Analysis of Schizophrenic State with Depersonalization. International Journal of Psycho-Analysis, 28, pp. 111-131.

(1965) Psychotic States: A Psychoanalytic Approach, New York: International Universities Press

Rudziński, R., (1978) Jaspers. Warszawa: Wiedza Powszechna.

Silver, A., L. (2005) Silvano Arieti: Remembering his message. Psilogos,
2 (1), 23-38.

Sowa, J. (1984) Kulturowe założenia pojęcia normalności w psychiatrii. PWN, Warszawa.

Spiegelberg, H. (1972) Phenomenology in Psychology and Psychiatry. Northwestern University Press, Evanston.

Stern, K. (1975) Love and Success, and other essays. New York: Farrar, Straus and Giroux.

Szałek, P. (2004) Psychoanaliza dzieci wedtug Melanii Klein. Acta Universitatis Lodzensis. Folia Philosophica, 16, pp. 143-160. --- (2007) Psychoterapia analityczna. Między naturalizmem a kulturalizmem. Łódź: Wydawnictwo Uniwersytetu Łódzkiego. 